\title{
Diverse manifestations of coronary vasculopathy in a transplanted heart
}

\author{
Natalia Wiligórska, Małgorzata Sobieszczańska-Małek, Tomasz Zieliński \\ Department of Heart Failure and Transplantology, National Institute of Cardiology, Warsaw, Poland
}

Correspondence to:

Prof. Małgorzata Sobieszczańska-Małek, MD, PhD, Department of Heart Failure and Transplantology, National Institute of Cardiology, ul. Alpejska 42, 04-628 Warszawa, Poland, phone: +48223434483 , email: m.sobieszczanska@ikard.pl Received: May 19, 2020. Revision accepted: June 29, 2020. Published online: July 7, 2020. Kardiol Pol. 2020; 78 (10): 1043-1044

doi:10.33963/KP.15498 Copyright by the Author(s), 2020
Cardiac allograft vasculopathy (CAV) is an important cause of morbidity and mortality in patients after heart transplantation (HT). Because of graft denervation, patients with CAV seldom present with typical anginal chest pain, often the first clinical presentation is progressive heart failure or sudden cardiac death. ${ }^{1}$ Due to those problems and possibility of occult presentation of CAV, annual endomyocardial biopsy in the first 5 years after HT should be performed as well as coronary angiography (CA) every 2 years. In experienced centers, the coronary angiography can be replaced with computed tomography. ${ }^{2}$ We present 2 scenarios of CAV to emphasize its heterogeneity.

The first case is a 79-year-old man 16 years after HT. He took low-dose pravastatin with ezetimibe due to statin-related myopathy. His medical history included stable concentration of immunosuppressive drugs without episodes of rejection. Nine years after HT, we observed stable lesions in the left anterior descending artery (LAD) and multiple lesions in the left posterior descending coronary artery. Two years later, percutaneous coronary intervention with implantation of 2 stents was performed due to significant stenoses in the bifurcation of the LAD and the diagonal branch and implantation of 1 stent in the proximal LAD. Further percutaneous coronary interventions were performed 3 years later, that is, 4 stents implantation in the left circumflex artery (LCA), LAD and the left main artery (FIGURE 1A). During 2-year follow-up, restenosis in the proximal LAD was observed on computed tomography. The patient had no chest pain and global left ventricular contractility was slightly impaired, ejection fraction was $45 \%$ to $50 \%$.
However, CAV can have a completely different course, as seen in a 9-year follow-up of a 31-year-old woman. In her medical history, she had one episode of recurrent cytomegalovirus $(\mathrm{CMV})$ infection with decreased left ventiruclar ejection fraction of $40 \%$ and she was suspected of irregular intake of immunosuppression. Eight years after HT, she was hospitalized due to epigastric pain and decreasing exercise tolerance. Echocardiography revealed worsening of left ventricular function with no segmental contractility disorders. On admission, acute cellular rejection and CMV infection were excluded. Coronary angiography revealed stenoses of the LAD, an occlusion of the LCA with retrograde blood supply. There were no significant changes in CA 1 year earlier (FIGURE $1 \mathrm{~B}$ and $1 \mathrm{c}$ ). Because of progressive fibrosis on cardiac magnetic resonance (FIGURE 1D), the patient was referred for retransplantation. During the waiting period, ischemic heart disease progressed and was complicated by severe cardiogenic shock. The biventricular assist device was implanted as a bridge to retransplantation. In next days, she died due to complications of mechanical circulatory support (ischemic stroke, pneumonia).

Cardiac allograft vasculopathy can appear as diffuse stenoses without typical angina over the years or can develop rapidly (characterized by concentric fibrous intimal hyperplasia along coronary vessels). ${ }^{2}$ It is important to remember that classic cardiovascular and transplant-associated risk factors (CMV infection, episodes of rejection, and irregular treatment) can be responsible for $\mathrm{CAV}$ development. ${ }^{3,4}$ It is very important to develop noninvasive procedures (ie, echocardiography) for early diagnosis of lesions caused by immunological mechanisms in the myocardium. ${ }^{5}$ 

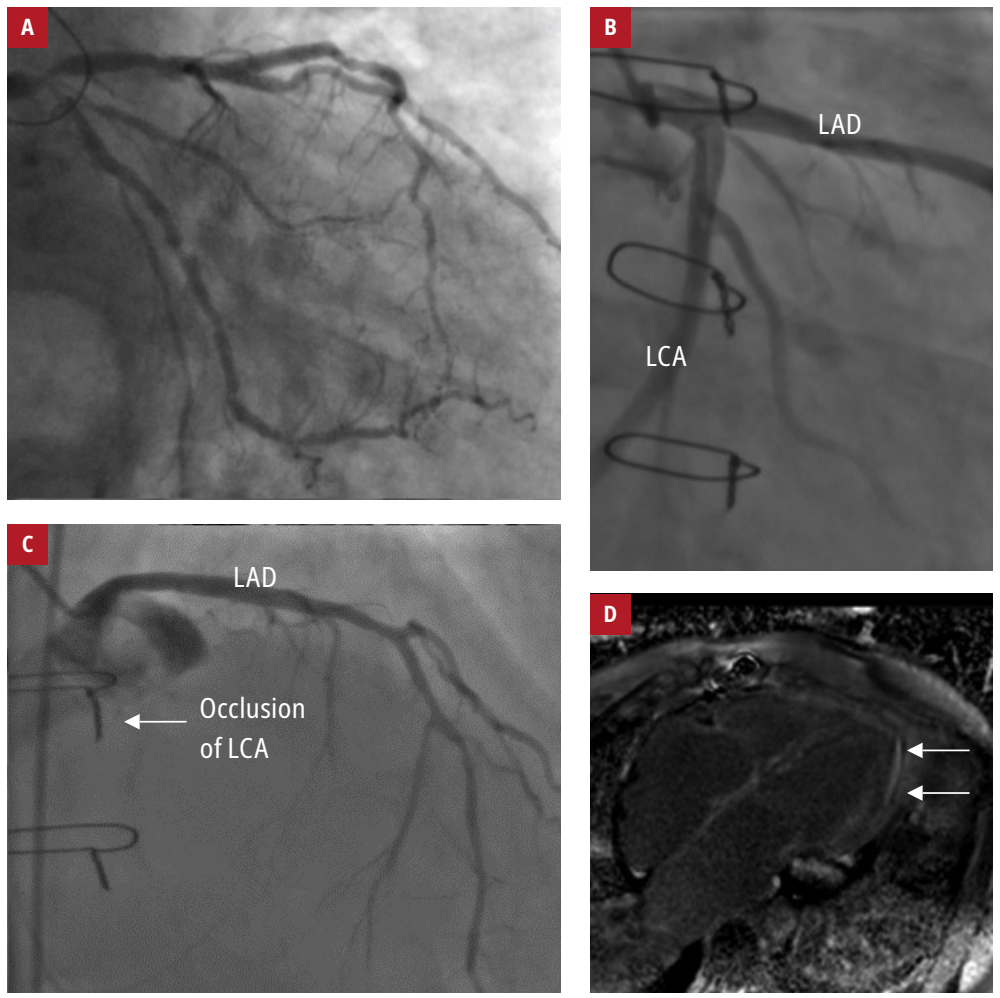

FIGURE 1 A - coronary angiography of the 1st patient (courtesy of A. Dębski); B - coronary angiography of the left coronary artery of the 2nd patient showing the left anterior descending artery (LAD) and left circumflex artery (LCA) (courtesy of $Ł$. Kalińczuk); C - coronary angiography of the left coronary artery of the 2nd patient performed 1 year later showing an occlusion of the LCA (arrow; courtesy of $€$. Kalińczuk); D - cardiac magnetic resonance of the 2nd patient showing progressive fibrosis (arrows; courtesy of M. Marczak)

We assume that CAV triggered by immune insults can progress more rapidly and have more serious clinical consequences.

\section{ARTICLE INFORMATION}

CONFLICT OF INTEREST None declared.

OPEN ACCESS This is an Open Access article distributed under the terms of the Creative Commons Attribution-NonCommercial-NoDerivatives $4.0 \mathrm{In}$ ternational License (CC BY-NC-ND 4.0), allowing third parties to download articles and share them with others, provided the original work is properly cited, not changed in any way, distributed under the same license, and used for noncommercial purposes only. For commercial use, please contact the journal office at kardiologiapolska@ptkardio.pl.

HOW TO CITE Wiligórska N, Sobieszczańska-Małek M, Zieliński T. Diverse manifestations of coronary vasculopathy in a transplanted heart. Kardiol Pol. 2020; 78: 1043-1044. doi:10.33963/KP.15498

\section{REFERENCES}

1 Skorić B, Čikeš M, Maček J, et al. Cardiac allograft vasculopathy: diagnosis, therapy, and prognosis. Croat Med J. 2014; 55: 562-576.

2 Kępka C, Sobieszczańska-Małek M, Pręgowski J, et al. Usefulness of dual-source computed tomography for the evaluation of coronary arteries in heart transplant recipients. Kardiol Pol. 2012; 70: 1111-1119.

3 Szygula-Jurkiewicz B, Szczurek W, Gąsior M, Zembala M. Risk factors of cardiac allograft vasculopathy. Kardiochir Torakochirurgia Pol. 2015; 12: 328-333.

4 Sobieszczańska-Małek M, Korewicki J, Komuda K, et al. Heart Transplantation an d Risk of Cardiac Vasculopathy Development: What Factors Are Important? Ann Transplant. 2017; 22: 682-688.

5 Antończyk K, Szulik M, Zakliczyński M, et al. Recurrent asymptomatic acute cellular rejection after heart transplantation: monitoring with speckle-tracking echocardiography. Pol Arch Intern Med. 2016; 126: 700-703. 